\title{
Operation room management in Korea: results of a survey
}

\section{Joonchul Jang, Hyong Hwan Lim, Goeun Bae, Sung Uk Choi, and Choon Hak Lim}

\author{
Department of Anesthesiology and Pain Medicine, Korea University Anam Hospital, Korea University College of \\ Medicine, Seoul, Korea
}

Background: The current state of general hospital operation room (OR) in Korea and how these ORs are being operated remain unclear. Therefore, the aim of this study was to investigate and assess the current state of OR management and surgical scheduling in general hospitals of Korea.

Methods: A total of 92 anesthesiology training hospitals and 2 equivalent hospitals in Korea were targeted for the survey. Anesthesiologists in hospitals received questionnaires for OR, anesthetic managements and surgical scheduling directly or by phone from the beginning of October 2015 to the end of December 2015.

Results: Of the 94 hospitals that were targeted, 59 hospitals (62.7\%) responded to the survey. Of the 59 hospitals, 40 (67.8\%) had 500-1,000 beds, 36 (61.0\%) had 11-20 ORs. Most OR arrangements were made by residents and specialists in Anesthesiology Department (90\%). Most hospitals (47.4\%) in the response set performed total surgeries in the range of 10,000 to 20,000 annually. The proportion of emergency surgeries in the total surgeries was $2.8-55.0 \%$. Methods for predicting expected surgery time were arbitrarily decided by surgeons (61\%), anesthesiologist's experience (20\%), or by analyzing historical data using software (5\%).

Conclusions: This survey study could trigger active operational researches for OR efficiency. It might help hospital policy makers manage OR resources more efficiently.

Key Words: Operating rooms, Organization and adimistration, Surveys and questionnaires.

\section{Introduction}

The number of surgery cases in Korea was 3,302.89 per 100,000 people in 2013 [1]. This number has a gradual upward trend. Facing the ever increasing health care demand and competition with limited government support, hospitals are more

Corresponding author: Choon Hak Lim, M.D., Ph.D.

Department of Anaesthesiology and Pain Medicine, Korea University Anam Hospital, 73, Inchon-ro, Seongbuk-gu, Seoul 02841, Korea

Tel: 82-2-920-5632, Fax: 82-2-928-2275

E-mail: yourejoice@korea.ac.kr

Received: March 17, 2016.

Revised: May 17, 2016 (1st); May 24, 2016 (2nd).

Accepted: May 24, 2016.

Korean J Anesthesiol 2016 October 69(5): 487-491

http://dx.doi.org/10.4097/kjae.2016.69.5.487 and more aware of the need to use their resources as efficiently as possible [2]. Operation room (OR) is a major production unit in every hospital. It is also a challenging unit as it unites many stakeholders such as surgeons, nurses, and patients. Hospital management is characterized by scarce, costly, and interrelated resources [3]. For these reasons, strategic or tactical planning and scheduling OR activities have become major priorities for hospitals and OR managing committees [3].

To improve financial efficiency in OR, a variety of perspectives such as scheduling efficiency, operational efficiency (requiring work process redesign), practitioner-centered efficiency, and patient-centered efficiency have emerged as quality issues in the medical field [4-6]. To the best of our knowledge, no study has been performed to increase the efficiency of OR in Korea. Therefore, the objective of this study was to determine the current state of general hospital ORs in Korea and its management. We conducted a questionnaire survey to investigate and assess

(c) This is an open-access article distributed under the terms of the Creative Commons Attribution Non-Commercial License (http://creativecommons.org/ licenses/by-nc/4.0/), which permits unrestricted non-commercial use, distribution, and reproduction in any medium, provided the original work is properly cited. 
the current state of OR operation and surgical scheduling in general hospitals of Korea to help establish efficient OR operational system in the future.

\section{Materials and Methods}

The study protocol was reviewed by the Institutional Review Board. It was approved as a minimal risk study without requiring individual consent based on institutional guidelines. Therefore, consent was waived.

Starting from the set of Korean academic hospitals provided by the Korean Hospital Association, we targeted 92 anesthesiology training hospitals and 2 equivalent hospitals in Korea. Anesthesiologists in the hospitals received questionnaires directly or by phone from the beginning of October 2015 to the end of December 2015. Our search eventually resulted in 59 hospitals (both private and public) equipped with functional OR. Their answers were registered on an electronic questionnaire by the respondent or the questioner. We preferred this method to regular postal services as it allowed automated registration of answers in a spreadsheet. Moreover, this method is quicker, more costeffective, and more user-friendly compared to regular postal services.

The questionnaire was kept as brief as possible (a printout of about 3 A4 pages). It covered general questions about the hospital and issues related to OR management, scheduling process for both elective and emergency surgeries. For most questions that were either quantitative or qualitative in nature, we suggested a list of possible answers. Participating hospitals received a summary of the results afterwards.

\section{A}

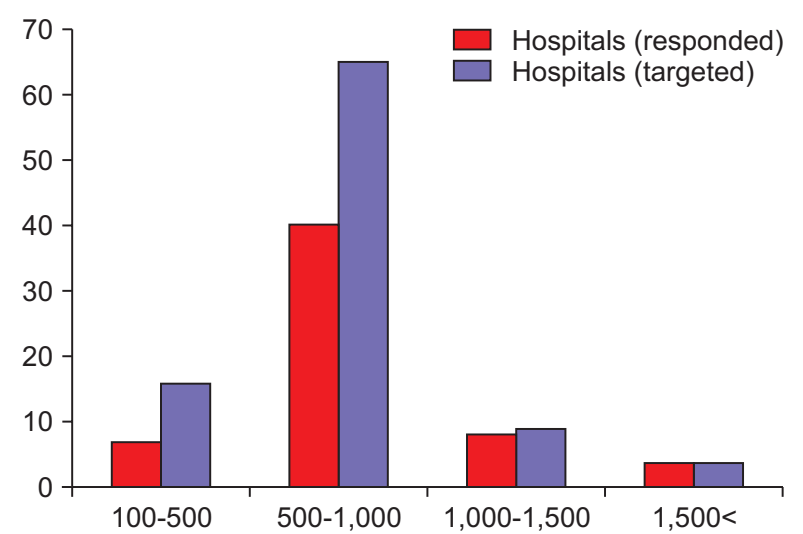

\section{Results}

\section{Response}

Of the 94 hospitals that we initially targeted, 59 (62.7\%) responded to the survey, including 57 anesthesiology training hospitals and 2 equivalent hospitals. Hospitals connected to School of Medicine in Korea were all included in the responded hospitals. The numbers of beds in the targeted 94 hospitals and the 59 hospitals that actually responded to the survey were compared to each other (Fig. 1A).

\section{Hospital beds and OR}

Sixty-five (69.1\%) of the total 94 hospitals and 40 (67.8\%) of the 59 hospitals that completed the survey had 500-1,000 beds. Thirty-six (61\%) of the 59 responded hospitals had 11-20 ORs (Fig. 1B). The higher the number of hospital beds, the higher the number of ORs (correlation coefficient $=0.85$ ). Sixty-three percent of the responded hospitals were satisfied with their current OR capacities. However, $37 \%$ of these hospitals were not satisfied with their current OR capacities due to insufficient OR.

\section{OR managements}

ORs were mainly (61\%) managed by anesthetic residents. Approximately $29 \%$ ORs were managed by anesthetic staffs. Only $2 \%$ ORs were managed by nurses. OR management software program was not used in any hospital.

The most important objective in OR managements was questioned. About $43 \%$ of respondents indicated that high utilization of ORs was the most important objective. It had the highest

B

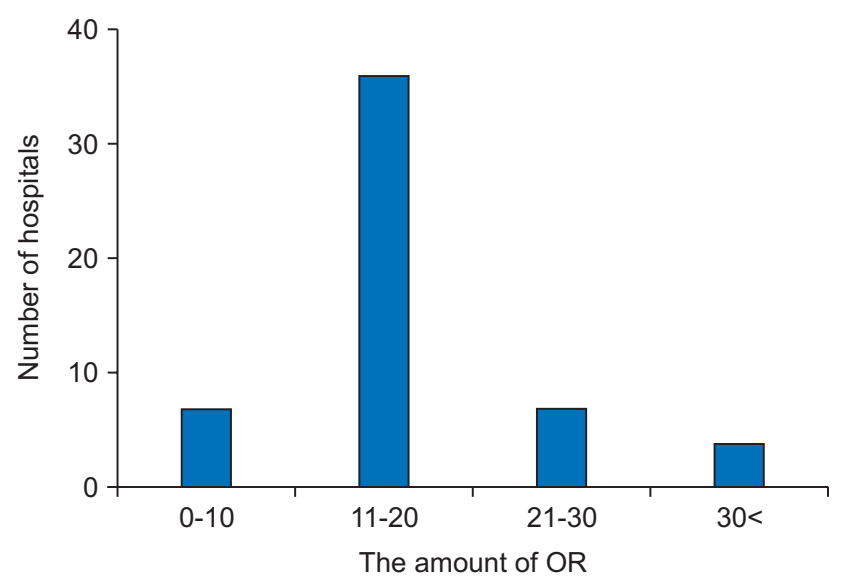

Fig. 1. (A) The numbers of beds in the targeted 94 hospitals and the 59 hospitals that responded to the survey. (B) The amount of OR in the set of respondent hospitals. 
score among all objectives. Avoiding overtime in the ORs also seemed to be highly important (32\%). Throughput/lead time (the time between scheduling surgeries and completing the scheduled surgeries), preferences surgical start time and OR structure of surgeon, or anesthesiologist did not seem to be of major interest to respondents $(10 \%, 3 \%$, and $2 \%$, respectively).

Methods for obtaining expected surgery time were questioned. Three approaches were applied in hospitals in order to estimate surgery durations. Surgery duration was either arbitrarily decided by a surgeon (61\%), anesthesiologist's experience (20\%), or by analyzing historical data using software (5\%).

\section{OR management committee}

The OR management committee provides advice and consultation on the function and performance of ORs, including operational efficiency, quality, safety, and service. Most of these hospitals (86\%) had an OR management committee. The chairs of the OR management committee were either anesthesiologists (66\%), surgeons (17\%), or administrators (9\%).

\section{Anesthetic managements}

\section{Preanesthesia evaluation clinics (PEC)}

We surveyed whether these hospitals had PEC. Most of these hospitals (75\%) did not have PEC. Only 25\% of these responded hospitals operated PEC.

\section{Assignment of anesthetic nurse to $O R$}

Assignment of one nurse to several rooms was the most common (at 34\%), followed by assignment of one nurse to every room (at 32\%) and assignment of one monitoring nurse to a specific OR (at 19\%).

\section{A}

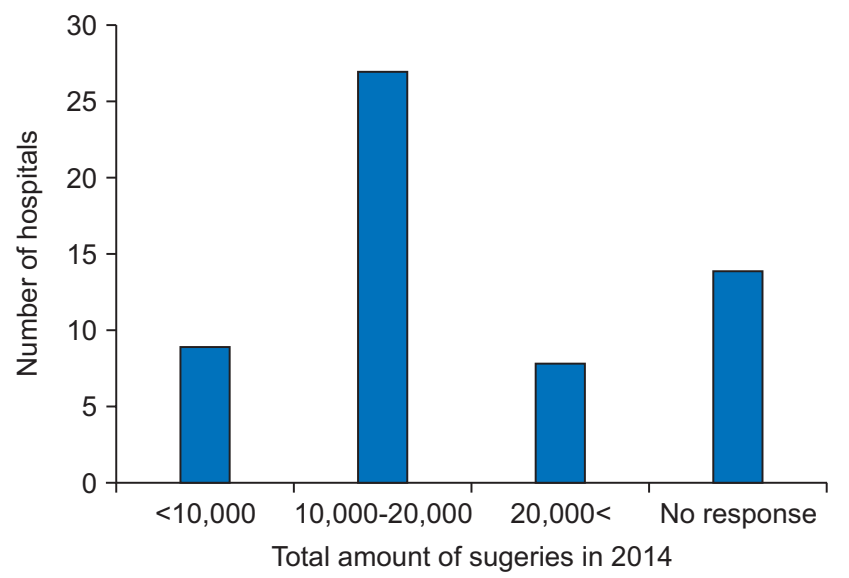

\section{Electric anesthetic records (EMR)}

Forty $(67.8 \%)$ of the 59 responded hospitals did not have electric anesthetic records. Only 18 hospitals (30.5\%) had electric anesthetic records.

\section{Amount of surgeries and emergency surgeries}

The total amount of surgeries and emergency surgeries performed in 2014 were surveyed. Most (47\%) hospitals in the response set performed annual surgeries of 10,000 to 20,000 (Fig. $2 \mathrm{~A})$. The proportion of emergency surgeries in total surgeries was $2.8-55.0 \%$. However, 10 to $30 \%$ emergency surgeries were performed in 32 hospitals (54\%) of the 59 responded hospitals (Fig. 2B).

The more the number of OR, the higher the number of total surgeries performed, including surgeries requiring general anesthesia and surgeries under local or regional anesthesia (correlation coefficient $=0.84$ ). Similarly, the more the number of OR, the higher the number of emergency surgeries (correlation coefficient $=0.61$ ).

We surveyed whether these hospitals had dedicated OR for emergency surgeries. Only 17\% of them had dedicated OR. However, anesthetic nurses and anesthesiologists were not designated for emergency surgeries.

\section{Elective surgeries on Saturdays}

Eighteen hospitals (30.5\%) of responded hospitals routinely performed elective surgeries on Saturdays. The remaining hospitals did not perform elective surgeries on Saturdays.

\section{Discussion}

The proportion of emergency surgery and current state of OR management were surveyed in this study. For general sur-

B

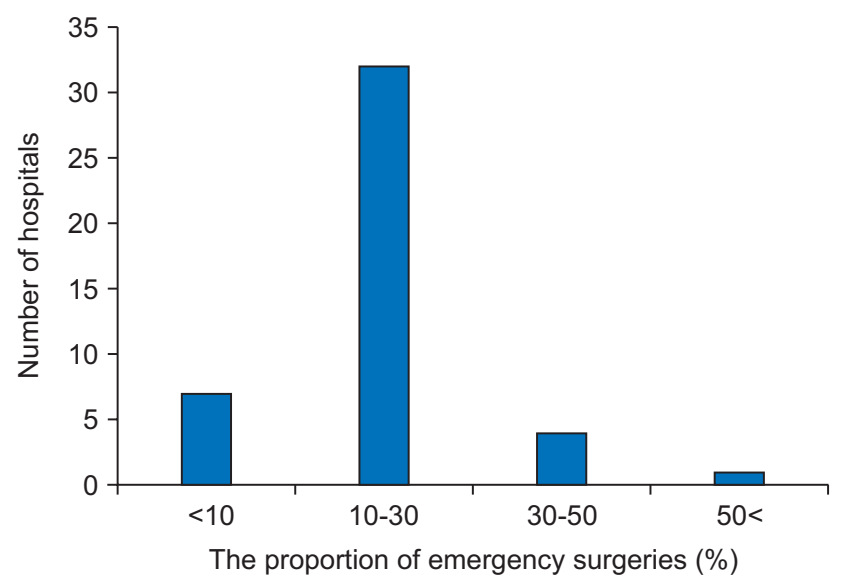

Fig. 2. (A) Total amount of surgeries in 2014. (B) The proportion of emergency surgeries in hospitals. 
gical emergencies, around $10 \%$ of operations in high-income countries and $21-90 \%$ in low- to middle- income countries are performed $[7,8]$. According to the American College of Surgeons National Surgical Quality Improvement Program data, an average of $14.7 \%$ of surgeries performed in 198 U.S. hospitals between 2005 and 2008 were emergency surgeries [9]. Although more than half of responded Korean hospitals had 10-30\% operations performed in the form of emergency surgeries, this survey showed wide variations in emergency surgeries performed (from 2.8 to $55.0 \%$ ). Cancer dedicated and specialized hospitals had the lowest percentages of emergency surgeries performed. On the contrary, hospitals that had not any other large scale hospitals nearby had higher proportion of emergency surgeries. Therefore, demands for dedicated emergency ORs has been raised to improve the efficiency of the emergency surgeries. Dedicated ORs for emergency cases has been reported to improve quality of care by decreasing cancellations and overruns in elective rooms [10]. However, using dedicated ORs for orthopedic trauma cases remains controversial. Emergency patients could be operated more efficiently on elective ORs instead of dedicated emergency ORs [11,12]. Further study is needed to investigate OR efficiency and waiting time for emergency operations.

There might be differences in the current state of OR management and surgical scheduling between the targeted 94 hospitals and the 59 hospitals that actually responded to the survey. However, since the percent deviations of the total 94 hospitals and of the 59 hospitals that completed the survey had 100-500, $500-1,000,1,000-1,500$ and $>1,500$ beds were below $5 \%$, we considered the bias to be negligible. Therefore, the response set could represent resident training hospitals of Korea.

To maximize OR utilization, better estimates of case duration lengths are needed. Only 5\% hospitals of responded sets used software to analyze historical data. This is much lower than the $30 \%$ of software utilization rate in a survey reported by Flanders [3]. The duration of operative procedures could be modeled as a lognormal variable with mean and standard deviations obtained by historic operative data. However, a regression methodology to predict case length has been reported to be a promising method in decreasing uncertainty about surgical case length than the standard method of surgical length prediction using historical means [13]. A recent computerized simulation study has demonstrated that using a predictive modeling system by incorporating patient and surgery-specific factors is superior to scheduling with duration prediction based on historical means per surgeon in both throughput and OR efficiency [14].

This survey revealed that OR arrangements were mainly performed by anesthetic residents and staffs in $90 \%$ of the responded hospitals. OR managers are responsible of determining the OR capacity and assigning capacity to different medical special- ists. Increases in the efficiency of using ORs can result in more production and more revenue for the hospital. However, operational management courses are currently lacking in the Korean academic educational programs. It should be considered in the research and education areas. Educational tools can help OR managers learn the consequences triggered by their operational policy and managerial decisions. OR efficiency can be affected by the personalities of OR managers in risk-taking in planning schedules. Risk-averse OR managers might cancel elective cases scheduled for surgery compared to a risk-taking OR managers [15]. In addition, OR managers need to frequently communicate and negotiate with various stakeholders, such as anesthesiologists, surgeons, and other OR staff. Significant improvements in OR efficiency can be achieved by better organizing the flow of work. In addition, multi-disciplinary efforts of surgeons, anesthesiologists, and nurses supervised and integrated by OR managers are necessary [16]. Education for management-related skill areas such as communication, human relation skills, use of supervisory power, and self-assessing tools for his/her risk appreciation could be helpful in training anesthetic residents.

This survey revealed that $15 \%$ of the responded hospitals had PEC. It has been reported that PEC can minimize cancellation rate and reduce any adverse effects of surgeries or procedures, thus increasing the level of satisfaction of both patients and surgeons while reducing medical costs for regularly scheduled surgeries [17-21]. However, there are specific and unique personnel and system requirements for the accumulation of multidisciplinary information in PEC. The justification for this type of program is that cost saving can be realized by decreasing wasted operating room time due to inadequate or incomplete patient preparation [22]. Financial efficiency and patient-centered efficiency might have conflicting interests and operating PEC should be considered in terms of hospital policy.

Nursing staffing to patient ratios and their education level have great impact on hospital mortality [23,24]. However, unfortunately there is no recommended nursing staff ratio in OR or in a post-anesthesia setting. Meanwhile, factor in different roles of nurses (monitoring patients or assisting anesthesiologists) should be considered.

In conclusion, we conducted a questionnaire survey to investigate and assess the current state of OR operation and surgical management in general hospitals of Korea. This survey study might trigger active operational researches for OR efficiency. It might help hospital policy makers manage OR resources more efficiently.

\section{Acknowledgments}

This work was supported by Korea University grants. 


\section{ORCID}

Joonchul Jang, http://orcid.org/0000-0001-5933-277X

Sung Uk Choi, http://orcid.org/0000-0003-3609-2253

\section{References}

1. 2013 Statistical Yearbook of major surgery [Internet]. Wonju (KR): National Health Insurance Service; 2014 Dec 31 [cited 2016 Feb 24]. Available from http://www.nhis.or.kr/bbs7/attachments/15841.

2. Eaton L. Trusts cancel $10 \%$ of operating theatre sessions. BMJ 2002; 324: 1174.

3. Cardoen B, Demeulemeester E, Beliën J. Operating room planning and scheduling: a literature review. Eur J Oper Res 2010; $201: 921-32$.

4. Archer T, Macario A. The drive for operating room efficiency will increase quality of patient care. Curr Opin Anaesthesiol 2006; 19: 171-6.

5. Baumgart A, Schüpfer G, Welker A, Bender HJ, Schleppers A. Status quo and current trends of operating room management in Germany. Curr Opin Anaesthesiol 2010; 23: 193-200.

6. Marjamaa R, Vakkuri A, Kirvelä O. Operating room management: why, how and by whom? Acta Anaesthesiol Scand 2008; 52: 596-600.

7. Shafi S, Aboutanos MB, Agarwal S Jr, Brown CV, Crandall M, Feliciano DV, et al. Emergency general surgery: definition and estimated burden of disease. J Trauma Acute Care Surg 2013; 74: 1092-7.

8. Smith M, Hussain A, Xiao J, Scheidler W, Reddy H, Olugbade K Jr, et al. The importance of improving the quality of emergency surgery for a regional quality collaborative. Ann Surg 2013; 257: 596-602.

9. Ingraham AM, Cohen ME, Raval MV, Ko CY, Nathens AB. Comparison of hospital performance in emergency versus elective general surgery operations at 198 hospitals. J Am Coll Surg 2011; 212: 20-28. e1.

10. Heng M, Wright JG. Dedicated operating room for emergency surgery improves access and efficiency. Can J Surg 2013; 56: 167-74.

11. Bhattacharyya T, Vrahas MS, Morrison SM, Kim E, Wiklund RA, Smith RM, et al. The value of the dedicated orthopaedic trauma operating room. J Trauma 2006; 60: 1336-40.

12. Wullink G, Van Houdenhoven M, Hans EW, van Oostrum JM, van der Lans M, Kazemier G. Closing emergency operating rooms improves efficiency. J Med Syst 2007; 31: 543-6.

13. Kougias P, Tiwari V, Orcutt S, Chen A, Pisimisis G, Barshes NR, et al. Derivation and out-of-sample validation of a modeling system to predict length of surgery. Am J Surg 2012; 204: 563-8.

14. Kougias P, Tiwari V, Berger DH. Use of simulation to assess a statistically driven surgical scheduling system. J Surg Res 2016; 201: 306-12.

15. Stepaniak PS, Mannaerts GH, de Quelerij M, de Vries G. The effect of the Operating Room Coordinator's risk appreciation on operating room efficiency. Anesth Analg 2009; 108: 1249-56.

16. Sokolovic E, Biro P, Wyss P, Werthemann C, Haller U, Spahn D, et al. Impact of the reduction of anaesthesia turnover time on operating room efficiency. Eur J Anaesthesiol 2002; 19: 560-3.

17. Parker BM, Tetzlaff JE, Litaker DL, Maurer WG. Redefining the preoperative evaluation process and the role of the anesthesiologist. J Clin Anesth 2000; 12: 350-6.

18. Cantlay KL, Baker S, Parry A, Danjoux G. The impact of a consultant anaesthetist led pre-operative assessment clinic on patients undergoing major vascular surgery. Anaesthesia 2006; 61: 234-9.

19. Flynn BC, Silvay G. Value of specialized preanesthetic clinic for cardiac and major vascular surgery patients. Mt Sinai J Med 2012; 79 : 13-24.

20. Correll DJ, Bader AM, Hull MW, Hsu C, Tsen LC, Hepner DL. Value of preoperative clinic visits in identifying issues with potential impact on operating room efficiency. Anesthesiology 2006; 105: 1254-9.

21. Farasatkish R, Aghdaii N, Azarfarin R, Yazdanian F. Can preoperative anesthesia consultation clinic help to reduce operating room cancellation rate of cardiac surgery on the day of surgery? Middle East J Anaesthesiol 2009; 20: 93-6.

22. Ferrari LR. Preoperative evaluation of pediatric surgical patients with multisystem considerations. Anesth Analg 2004; 99: 1058-69.

23. Aiken LH, Sloane DM, Bruyneel L, Van den Heede K, Griffiths P, Busse R, et al. Nurse staffing and education and hospital mortality in nine European countries: a retrospective observational study. Lancet 2014; 383: 1824-30.

24. Silber JH, Rosenbaum PR, McHugh MD, Ludwig JM, Smith HL, Niknam BA, et al. Comparison of the value of nursing work environments in hospitals across different levels of patient risk. JAMA Surg 2016; 151: 527-36. 